\title{
Diabetic cases controlled with low carbohydrate diet (LCD) and GLP-1 receptor agonist (GLP-1 RA)
}

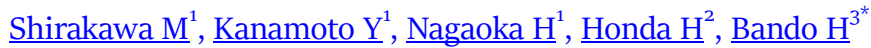

${ }^{1}$ Shishikui Clinic, Kaiyo, Kaifu-gun, Tokushima, Japan

${ }^{2}$ Minami Hospital, Minami, Kaifu-gun, Tokushima, Japan

${ }^{3}$ Tokushima University / Medical Research, Tokushima, Japan

Corresponding Author: Hiroshi Bando, MD, PhD, FACP

Address: Tokushima University /Medical Research, Nakashowa 1-61, Tokushima 770-0943, Japan.

Received date: 26 March 2019; Accepted date: o8 April 2019; Published date: 16 April 2019

Citation: Shirakawa M, Kanamoto Y, Nagaoka H, et al., "Diabetic cases controlled with low carbohydrate diet (LCD) and GLP-1 receptor agonist (GLP-1 RA)”. Asp Biomed Clin Case Rep, vol.2, no.s1: 38-46, 2019.

Copyright (C) 2019 Shirakawa M, Kanamoto Y, Nagaoka H, et al., This is an open access article distributed under the Creative Commons Attribution License, which permits unrestricted use, distribution, and reproduction in any medium, provided the original work is properly cited.

\begin{abstract}
Recent treatment for type 2 diabetes mellitus (T2DM) has included glucagon-like peptide-1 receptor agonist (GLP-1 RA), indicating clinical efficacy for better glucose variability. Subjects were seven patients with T2DM associated with the obese tendency. Their average age was $63.8 \pm 21.7$ years old ( 5 males, 2 females) who received a new administration of GLP-1 RA (Mean \pm standard deviation). For GLP-1 RA, dulaglutide (TRULICITY ${ }^{\mathrm{R}}$, singledose pen) was administered by subcutaneous injection $0.75 \mathrm{mg}$ once a week. Basal data at o month revealed that body weight $76.0 \pm 11.6 \mathrm{~kg}$, body mass index (BMI) $29.2 \pm 11.6$, blood C-peptide immunoreactivity (CPR) $2.68 \pm$ $0.49 \mathrm{ng} / \mathrm{mL}$, respectively. After the intervention of dulaglutide, decreased value of BMI for 3 and 6-9 months was $0.78 \pm 0.45$ and $1.16 \pm 0.85$, and HbA1c for 3 and 6-9 months was $1.60 \pm 1.52 \%$ and $2.01 \pm 1.44 \%$, respectively. Though these cases have various complications besides T2DM, they showed clinical effects of weight reduction and lowering blood glucose. Diabetic treatment for current cases would suggest that GLP-1 RA would be effective in various situations such as a super-aged patient, medical practice in the remote area, family care and visiting nursing.
\end{abstract}

\section{Keywords}

Low Carbohydrate Diet (LCD); GLP-1 Receptor Agonist (GLP-1 RA); Dulaglutide; Type 2 Diabetes Mellitus (T2DM); Dipeptidyl Peptidase-4 (DPP-4) Inhibitor; Intestine Secretion Insulin (INCRETIN)

\section{Abbreviation}

Glucagon-Like Peptide-1 (GLP-1); GLP-1 Receptor Analogue (GLP-1 RA); Calorie Restriction Diet (CRD); Low Carbohydrate Diet (LCD); Mediterranean Diet (MD); Gastric Inhibitory Polypeptide (GIP); Type2 Diabetes Mellitus (T2DM); Dipeptidyl Peptidase-4 (DPP-4) ; Fasting Blood Glucose (FBG)

\section{Introduction}

Diabetes has been increasing steadily in developing and also developing countries [1]. It is a crucial disease that must be resolved all over the world today.
It influences much in the wide range of fields, medically, socially and economically. Because of developing macroangiopathy and microangiopathy, diagnosis and treatment are required from various 
viewpoints [2].

The International Diabetes Federation (IDF), the American Diabetes Association (ADA) and the European Association for the Study of Diabetes (EASD) have compiled standard guidelines for their management [3]. Among them, one of the recent attention is the diet. There are some known kinds of diet methods, which are Calorie Restriction Diet (CRD), Low Carbohydrate Diet (LCD), Mediterranean diet (MD) and others. These nutritional therapies have been reported and discussed for long. Thus, the comparison between CRD and LCD has been particularly in focus until now $[4,5]$.

LCD was originally proposed by Atkins et al., in which short-term weight loss and blood sugar improvement effects have been reported [6]. After that, comparisons were made for diets such as LCD, $\mathrm{CRD}, \mathrm{MD}$, etc. and the clinical usefulness of LCD was reported by Shai et al. [7]. These are the ongoing clinical studies of LCD in the North American and the European region.

On the other hand, in Japan, a group of authors started LCD and have developed in the clinical practice and research field. Initially, Ebe et al. have reported LCD method for the first time [8]. Consequently, by applying LCD at the clinical situation, the research group proposed petite-LCD, standard-LCD and superLCD as three types of LCD [9]. As a result, many patients and general people can apply LCD for medical treatment and health promotion. Movement for LCD has been spread in the activities of Japan LCD Promotion Association (JLCDPA) through more books and workshops. Furthermore, in clinical studies, we have reported elevated blood ketone bodies in the axis of fetuses, placentas, neonates and pregnant women, and reported the physiological important role of ketone bodies [10].

When LCD is actually applied to diabetic patients, the average blood glucose and mean amplitude of glycemic excursions (MAGE) could be decreased. Consequently, the profile of blood glucose will be clinically improved, indicating the efficacy of LCD. In fact, however, there are not so many diabetic patients who showed successful results by LCD due to various reasons. The authors have clinical experience for many diabetes patients, with lots of struggled management among them.

One of the developments for diabetic research has been the presence of intestine secretion insulin (INCRETIN). Consequently, gastric inhibitory polypeptide (GIP) was identified by purification of intestinal hormone and glucagon-like peptide-1 (GLP1) indicating the action of the incretin action was reported [11]. After that, several studies showed the functional role and mechanism of GLP-1 [12]. Its physiological role includes various functions, such as inhibiting glucagon secretion, stimulating insulin secretion, increasing glucose production and glucose uptake in the liver, promoting glucose uptake and glycogen production in muscle, reducing food intake for the central nerve system and delay of gastric emptying [13]. For the treatment of patients with diabetes, GLP-1 receptor analogue (GLP-1 RA) and also Dipeptidyl peptidase-4 (DPP-4) inhibitor have been recent topics associated with effective therapy.

Especially, GLP-1 RA has been known as highly effective anti-hyperglycemic agent with low risk of hypoglycemia and expectation for body weight reduction [14]. Several kinds of GLP-1 RA have been used in diabetic medical practice, and their efficacy has been recognized so far.

From mentioned above, authors have experienced the cases where GLP-1 RA has been administered to a diabetic patient who showed rather less beneficial efficacy from LCD method for nutritional therapy. Among them, we report and discuss here from various points of view.

\section{Patients and Methods}

The subjects enrolled in this study were 7 patients with type 2 diabetes mellitus (T2DM) associated with obese tendency. Their average age was $63.8 \pm 21.7$ years old (29 to 89 years, 5 males, 2 females) who received a new administration of GLP-1 RA at our clinic after January 201X. Average observation period (day) was $223 \pm 175$ days (90-598). In 6 cases out of 7 cases, DPP-4 inhibitor was discontinued and GLP-1 RA 
Citation: Shirakawa M, Kanamoto Y, Nagaoka H, et al., "Diabetic cases controlled with low carbohydrate diet (LCD) and GLP-1 receptor agonist (GLP-1 RA)”, Asp Biomed Clin Case Rep, vol.2, no.s1: 38-46, 2019.

was started. In one case, GLP-1 RA was started from the beginning.

For the administration of GLP-1 RA, dulaglutide was used, where the trade name is TRULICITY ${ }^{\mathrm{R}}$ with subcutaneous injection $0.75 \mathrm{mg}$ (single-dose pen) [15]. It was administered once a week once. In the case of treatment for sulfonylurea agent, the dose was half of the standard. Before the initiation of GLP-1 agent, body weight, blood glucose, HbA1c value and blood C-peptide immunoreactivity (CPR) were measured.

As to the basal data, the mean pre-dose body weight was $76.0 \pm 11.6 \mathrm{~kg}$, the pre-dose mean BMI was $29.2 \pm 11.6$, and the pre-dose mean blood CPR $(\mathrm{ng} / \mathrm{ml}) 2.68 \pm 0.49$. The data of mean \pm standard deviation, minimum and maximum were shown in Table-1. There were no cases of discontinuation of administration due to serious reverse effects and other problems by the end of the observation period.

\begin{tabular}{|l|l|l|}
\hline \multicolumn{2}{|c|}{ Table-1: Summary of basal data in 7 subjects } \\
\hline & Mean \pm SD & Min - Max \\
\hline Age (years old) & $63.8 \pm 21.7$ & $29-89$ \\
\hline $\begin{array}{l}\text { Observation Period } \\
\text { (day) }\end{array}$ & $223 \pm 175$ & $90-598$ \\
\hline Body Weight (kg) & $76.0 \pm 11.6$ & $65.8-98.8$ \\
\hline BMI & $29.2 \pm 11.6$ & $25.1-39.1$ \\
\hline C-peptide (ng/ml) & $2.68 \pm 0.49$ & $1.7-3.3$ \\
\hline
\end{tabular}

\section{Results}

The decreased value of BMI in the observation period for 6-9 months was $1.16 \pm 0.85$. Among them, the mean reduction value for 3 months was $0.78 \pm 0.45$ (Table-2). On the other hand, the average HbA1c reduction value (\%) in the observation period for 6-9 months was $2.01 \pm 1.44 \%$. Similarly, the mean $\mathrm{HbA1c}$ reduction value (\%) for three months was $1.60 \pm 1.52 \%$ (Table-2). The data of minimum and maximum are also included in Table-2.
Table-2: Summary of results in 7 subjects

\begin{tabular}{|l|l|l|}
\hline & Mean \pm SD & Min - max \\
\hline $\begin{array}{l}\text { Decreased value of BMI } \\
\text { for 6-9 months }\left(\mathrm{kg} / \mathrm{m}^{2}\right)\end{array}$ & $1.16 \pm 0.85$ & -2.3 \\
\hline $\begin{array}{l}\text { Decreased value of BMI } \\
\text { for 3 months }\left(\mathrm{kg} / \mathrm{m}^{2}\right)\end{array}$ & $0.78 \pm 0.45$ & $0.2-1.6$ \\
\hline $\begin{array}{l}\text { Decreased value of HbA1c } \\
\text { for 6-9 months (\%) }\end{array}$ & $2.01 \pm 1.44$ & $0.2-3.3$ \\
\hline $\begin{array}{l}\text { Decreased value of HbA1c } \\
\text { for 3 months (\%) }\end{array}$ & $1.60 \pm 1.52$ & $0.4-3.2$ \\
\hline
\end{tabular}

\section{Case Presentation}

There are 7 patients with T2DM associated with various complications and situations, which were provided GLP-1 RA. These cases are described in the following.

\section{Case-1:}

The patient is an 89-year-old man who presents with chronic obstructive pulmonary disease (COPD) as a co-morbid medical problem. He had a cerebral infarction 17 years ago and has right hemiplegia and motor aphasia since then. He was admitted for pneumonia and rhabdomyolysis 5 years ago.

As a present history, he has given visiting home care due to COPD and heart failure for 5 years. He showed weight gain and exacerbated diabetes, leading to lower extremity arterial occlusion due to refractory right foot cellulitis. A strong intervention for glycemic control was required and was increased to $4 \mathrm{mg}$ of glimepiride. On regular visits in January 201X, he showed the following status: height $156 \mathrm{~cm}$, weight 61.0 kg, BMI 25.1, skin ulcers, right hemiplegia, and motor aphasia. Laboratory data revealed fasting blood glucose (FBG) $181 \mathrm{mg} / \mathrm{dl}$, HbA1c 9.4\%, and blood Cpeptide $3.3 \mathrm{ng} / \mathrm{ml}$.

Diagnoses were 1) T2DM, 2) Congestive heart failure, 3) Obstructive arteriosclerosis and intractable right foot cellulitis, 4) Cerebral infarction, 5) Obesity. We had taught diet therapy including LCD and/or $\mathrm{CRD}$, but he cannot obey or continue it. Even though he has given visiting rehabilitation, his weight was 
stable because of frequent snacks and less exercise in his daily life.

Then, his treatment changed by reduced glimepiride from $4 \mathrm{mg}$ to $2 \mathrm{mg} /$ day, discontinued DPP-4 inhibitor and administration of a GLP-1 RA. It can reduce severe hypoglycemia, heart failure, and body weight. After 7 months, body weight was decreased from $61.0 \mathrm{~kg}$ to $56.6 \mathrm{~kg}$, and glycemic control was also significantly improved to HbA1c $6.1 \%$. After that, the glimepiride was reduced to 1.5 $\mathrm{mg} /$ day, and the weight became stable at $56.0 \mathrm{Kg}$ and HbA1c 6.1\%.

\section{Case-2:}

The patient is a 29-year-old woman, who also has schizophrenia as a complication. Obesity and diabetes were originally present. After pregnant and birth, she had become uncontrolled diabetic states because of lack of exercise and inadequate meal habit. Consecutively, she was admitted for the treatment of schizophrenia, and treated by oral metformin + DPP4 inhibitor. Her status was $159 \mathrm{~cm}$ in height, $98.8 \mathrm{~kg}$ in weight, and BMI 39.1. Laboratory tests showed that FBG $237 \mathrm{mg} / \mathrm{dl}$, HbA1c 11.4\%, blood C-peptide 2.9 $\mathrm{ng} / \mathrm{ml}$.

From these diabetic situations, conventional treatment was considered to be difficult. She could not obey diet therapy of LCD or CRD, and then a GLP1 receptor agonist was started from January 201X. She had a weight reduction of $1.0 \mathrm{Kg}$, HbA1c $1.0 \%$ decrease with gradual efficacy of GLP-1 RA for 3 months. After 5 months, the weight dropped to $97 \mathrm{~kg}$ and HbA1c was $10.0 \%$. She had been admitted to the hospital for schizophrenia and diabetes. Her general status has been improved, and then she was discharged. At present, the body weight was decreased to $93.2 \mathrm{~kg}$, and $\mathrm{HbA1c} 8.2 \%$ with recently stable clinical course.

\section{Case-3:}

The patient is a 64-year-old male, who has some complications such as cerebral infarction with three times of events, hypertension, dyslipidemia and chronic kidney disease (CKD). As a medical history, insulin has been used before the recurrence of cerebral infarction. After relapse, he was referred to our hospital and controlled with oral medicine. He developed third cerebral infarction, and after discharge, he has been treated with anti-diabetic oral agents 2 years ago. His diet therapy was incomplete and lack of exercise due to paralysis has led him to rather poor diabetic control.

His physical examination included $170 \mathrm{~cm}$ in height, $77.7 \mathrm{~kg}$ in weight, 26.9 in BMI. Laboratory exams showed FBG $208 \mathrm{mg} / \mathrm{dl}$, HbA1c 8.9\%, blood Cpeptide $3.0 \mathrm{ng} / \mathrm{ml}$ at the start of administration for GLP-1 agonist (dulaglutide).

As the progress course after diagnosis, his diet therapy was started as a combination of LCD and CRD. Furthermore, glimepiride was reduced by half, DPP-4 inhibitor was discontinued, and dulaglutide was started. At 3 months after initiation, there was a weight loss of $2.2 \mathrm{~kg}$ and $\mathrm{HbA1c}$ decreased by $0.5 \%$. At 7 months for dulaglutide, the body weight dropped to $75.9 \mathrm{~kg}$ and HbA1c 7.8\%. He has had no remarkable adverse effects during these treatments.

\section{Case-4:}

The patient is a 68-year-old woman, and complications are hypertension, bilateral osteoarthritis (OA), and spinal stenosis with low back pain. As a present history, she has been diabetic and treated for 7 years. Two operations were performed for lumbar spinal stenosis, but lumbar disc herniation has been still found at present. She was introduced to our clinic because she must take care of her sick family at home and it is difficult to visit a large hospital in a remote area. After that, she has gained weight from lack of exercise and became a more uncontrolled diabetic status.

Her status was $152 \mathrm{~cm}$ in height, $68.5 \mathrm{~kg}$ in body weight, 29.6 in BMI. Her diabetes related tests at the start of administration showed that FBG $182 \mathrm{mg} / \mathrm{dl}$, HbA1c 8.1\%, and C-peptide in blood $2.7 \mathrm{ng} / \mathrm{ml}$. The clinical course after diagnosis, she was indicated to continue standard LCD. Clinical progress revealed 1.4 $\mathrm{kg}$ weight reduction and $\mathrm{HbA1c} 0.6 \%$ decrease of HbA1c in two months. At 3 months, her weight was $0.4 \mathrm{~kg}$ reduced and her HbA1c was $0.4 \%$ decreased. 
After 6 months, the body weight increased to $68.9 \mathrm{~kg}$ with HbA1c 7.9\%. Consequently, more appropriate therapeutic interventions are needed in the future.

\section{Case-5:}

The patient is a 35-year-old male who has been a smoker with dyslipidemia. As to his family history, grandfather and mother had T2DM, and mother had a myocardial infarction. He has been obese and diabetic for a long year. After educational hospitalization for diabetes, he has introduced to our clinic for successive treatment for diabetes three years ago. Consequently, oral medication of DPP-4 inhibitor and SGLT-2 RA were continued, associated with metformin later in our clinic. However, his adherence to medication has been very poor, and the glycemic control has become worsened.

Currently, his status has been that height $170 \mathrm{~cm}$, weight $79.8 \mathrm{~kg}$, BMI 27.6, FBG $279 \mathrm{mg} / \mathrm{dl}$, HbA1c $11.7 \%$ and blood C-peptide $2.3 \mathrm{ng} / \mathrm{ml}$. He was advised to continue adequate diet therapy with LCD and CRD. Regarding the treatment for diabetes, a DPP-4 inhibitor was discontinued, and GLP-1 RA was started. At 2 months, he had weight reduction of 2.3 $\mathrm{kg}$ and a $2.8 \%$ decrease of HbA1c value. At 3 months, the weight loss was $2.4 \mathrm{~kg}$, and HbA1c decrease was $4.1 \%$. After 4 months, his body weight was $75.5 \mathrm{~kg}$ and HbA1c was $7.4 \%$, with gradually improved diabetic state.

Case-6:

The patient is a 79-year-old male with complications of dementia, atrial fibrillation, and chronic heart failure. He had been originally not obesity for years and treated for atrial fibrillation and chronic heart failure. The patient's wife has been administering long-acting insulin with his support to some extent previously. However, he has been gradually with dementia state since 5 years ago. He shows the habit of overeating in a hidden situation from his family. Thus, He became obese due to lack of exercise and was recently diagnosed with T2DM.

His physical examination revealed that height 165 $\mathrm{cm}$, weight $81.0 \mathrm{~kg}$, and BMI 29.8. The diabetes related tests included FBG $150 \mathrm{mg} / \mathrm{dl}, \mathrm{HbA} 1 \mathrm{c} 7.7 \%$ and C-peptide $2.9 \mathrm{ng} / \mathrm{ml}$. Diet therapy seemed to be actually difficult because of dementia. In response to the administration of GLP-1 RA, body weight was decreased by $1 \mathrm{~kg}$ and $\mathrm{HbA1c}$ was decreased by $0.3 \%$ in one month. There were $1.7 \mathrm{~kg}$ of weight loss, HbA1c $0.6 \%$ decrease in 2 months. At 3 months the diabetic situation was that the weight was regained to $80.7 \mathrm{~kg}$, but HbA1c was improved to $6.9 \%$ with a moderate stable condition.

\section{Case-7:}

The patient is an 83-year-old male with type 2 diabetes, with the complication of hypertension and osteoarthritis (OA) on both knees. He has been treated for these diseases for nine years. A few years ago, he was hospitalized with a teaching education for diabetes and has been receiving DPP-4 inhibitor and sulfonylurea agent until now. Since he is living alone, however, he cannot continue adequate diet therapy, such as many snacks and lack of exercise due to OA on both knees. As a result, obesity worsened his QOL and $\mathrm{ADL}$, then the diabetes control has become in poor condition.

His physical examination showed $158 \mathrm{~cm}$ in height, $65.8 \mathrm{~kg}$ in weight, BMI 26.4, and diabetes related tests showed that FBG $229 \mathrm{mg} / \mathrm{dl}$, HbA1c 9.0\%, and serum C-peptide $1.7 \mathrm{ng} / \mathrm{ml}$. He cannot obey diet therapy, because he wanted to eat as he likes. One month after starting GLP-1 RA, body weight was decreased by 2.8 $\mathrm{kg}$, and HbA1c was decreased by $0.3 \%$. At two months, body weight decreased by $2.8 \mathrm{~kg}$, HbA1c decreased by $0.6 \%$. After 3 months, his weight was reduced to 62.0 $\mathrm{kg}, \mathrm{HbA1c} 7.8 \%$, and his clinical course has been better and stable.

As mentioned above, related data for 7 cases treated with GLP-1 RA are summarized in Table-3. There was a tendency of weight reduction and decreased HbA1c value in 3 months.

\section{Discussion}

Recently, the new anti-hyperglycemic agent has been developed, which is GLP-1 RA. It has a remarkable efficacy and safety profile distinct from 
other anti-diabetic agents [16]. GLP-1 has been reported to have several functions as follows: stimulating insulin secretion, inhibiting glucagon secretion, promoting glucose production and glucose uptake in the liver, increasing glucose uptake and glycogen production in skeletal muscle, decreasing food intake for the central nerve, delay of gastric emptying and so on [14].

From the physiological point of view, it is meaningful to compare the functions of three kinds of related hormones, which are GLP-1, gastric inhibitory polypeptide (GIP) and glucagon. These factors seem to have various effects on several organs, such as the brain, gastrointestinal tract, pancreas, liver, adipose tissue and bone [17]. Among them, GLP-1 and GIP is a pair of two incretin hormones, which are secreted from the gut for the ingestion of nutrients. Those two hormones can increase insulin secretion and also improve the glucose fluctuation after a meal [18]. GLP-1 and GIP both show the influence of decreased food intake for the brain.

In contrast, there seem to show the opposite effects in other organs. For the glucagon secretion from the pancreas, GLP-1 shows suppressive effect, and GIP shows stimulating effect. For bone metabolism, GLP-1 seems to have a stimulating effect on bone formation, and GIP seems to have suppressive effect for bone resorption [17].

One of the GLP-1 RA is dulaglutide, which is given only once a week. Some beneficial points include easy injection procedure, high blood glucose improving the effect and low frequency of antibody appearance. Further, it is practical and easy for patients who show cognitive impairment or poor compliance and require daily care and others. Regarding the clinical efficacy, it showed a dose-dependent reduction in HbA1c and acceptable safety profile in the randomized, doubleblind, placebo-controlled study [19].

There is a reason that dulaglutide can be injected once a week. Its degradation has been delayed because of DPP- 4 inhibition in the blood. The increase in molecular weight also reduces the absorption rate and clearance after the injection. Consequently, the half-life of blood concentration would be extended to 4-5 days, and thus its concentration in the blood would be rather maintained for one week [13]. From these situations, long-acting dulaglutide may bring better adherence and prevent the deterioration of Healthrelated Quality of Life (HRQOL).

There was a report concerning the comparison between once-weekly dulaglutide and once-daily liraglutide. On 52-week investigation, two groups of dulaglutide $0.75 \mathrm{mg} /$ week and Liraglutide $0.9 \mathrm{mg} /$ day showed $-1.39 \%$ and $-1.19 \%$, respectively, with slight superiority in the former [20]. Another study in western countries showed that they use the dose as twice value. From the paper on AWARD-6, two groups of dulaglutide $1.5 \mathrm{mg} /$ week and liraglutide $1.8 \mathrm{mg}$ /day at 26 weeks have the efficacy of decreasing of HbA1c. The results were equivalent that the former was $1.42 \%$ and the latter was $-1.36 \%$ [21].

The effect of dulaglutide was investigated in 855 patients with T2DM [22]. There were categorized into 4 groups by the age (border 65 years old) and BMI (border 25) as follows: 1) young and low-BMI, 2) young and high-BMI, 3) elderly and low-BMI, 4) elderly and high-BMI. The mean changes from baseline in HbA1c and body weight at 26 weeks were 1) $-1.69 \%$ and $-0.29 \mathrm{~kg}, 2)-1.48 \%$ and $-0.09 \mathrm{~kg}, 3)-$ $1.68 \%$ and $-0.20 \mathrm{~kg}, 4)-1.72 \%$ and $-0.26 \mathrm{~kg}$, respectively. Thus, dulaglutide improved $\mathrm{HbA1c}$ values regardless of the value of age and BMI.

Diabetes has been increasing anywhere, in urban and also remote areas. The first author has continued walk-in clinic for long years in rather remote area. There are several clinical problems with the initiation of injection therapy for diabetes. They include i) difficult staff education, ii) rejection of treatment by injection from patients, and iii) necessary assistance by families [23]. In particular, from the point of primary care medicine, management may be difficult in sparsely populated areas due to lack of manpower.

On the other hand, dulaglutide is convenient for only once-weekly administration. Its advantage would include excellent glycemic control, a constant dose of $0.75 \mathrm{mg}$, and simple useful device [14]. Therefore, we 
Citation: Shirakawa M, Kanamoto Y, Nagaoka H, et al., "Diabetic cases controlled with low carbohydrate diet (LCD) and GLP-1 receptor agonist (GLP-1 RA)”, Asp Biomed Clin Case Rep, vol.2, no.s1: 38-46, 2019.

could easily started dulaglutide for 7 cases in a sparsely populated area. There has been recently a clinical situation of injection for drug administration in the orthopedic region. Authors and staffs have lots of experiences to teach self-injection of teriparatide (Forteo $^{\mathrm{R}}$ subcutaneous injection kit 6oo $\mu \mathrm{g}$ ) for osteoporosis [24]. Therefore, it was rather easy to introduce and show how to manage it safely and efficiently.

As regard to 7 cases in this study, diet therapy including LCD and/or CRD was not so successful from bio-, psycho- and social points of view. It was necessary to adjust the dose of dulaglutide and other medicine [19]. In other words, the DPP-4 inhibitor was discontinued and GLP-1 preparation was administered except for case- 6 . The dose of sulfonylurea agent was reduced to half in cases 1, 3, 4 and 7. As a result, weight reduction and decreased HbA1c were found except for case-4 (Table-3). In particular, case- 1 was a home-based case, and then its management was difficult due to various complications. There were anorectic effect and suppression of deterioration of heart failure due to

\begin{tabular}{|c|c|c|c|c|c|}
\hline \multicolumn{6}{|c|}{ Table-3: Summary of 7 cases treated with GLP-1 RA (duraglutide) } \\
\hline Cases & $\begin{array}{l}\text { BMI at o } \\
\text { month }\end{array}$ & $\begin{array}{l}\text { CPR (ng/ml) At o } \\
\text { month }\end{array}$ & $\begin{array}{l}\text { CPI at o } \\
\text { month }\end{array}$ & $\begin{array}{l}\text { Weight } \\
o \rightarrow 3 \text { month }\end{array}$ & $\begin{array}{l}\text { HbA1c }(\%) o \rightarrow 3 \\
\text { month }\end{array}$ \\
\hline Case-1: $89 \mathrm{M}$ & 25.1 & $3 \cdot 3$ & 1.82 & $61.0 \rightarrow 57.5$ & $9.4 \rightarrow 6.2$ \\
\hline Case-2: $29 \mathrm{~F}$ & 39.1 & 2.9 & 1.22 & $98.8 \rightarrow 97.8$ & $11.4 \rightarrow 10.4$ \\
\hline Case-3: $64 \mathrm{M}$ & 26.9 & 3 & 1.44 & $77 \cdot 7 \rightarrow 75 \cdot 5$ & $8.9 \rightarrow 8.4$ \\
\hline Case-4: $68 \mathrm{~F}$ & 29.6 & 2.7 & 1.44 & $68.5 \rightarrow 68.1$ & $8.1 \rightarrow 7.7$ \\
\hline Case-5: $35 \mathrm{M}$ & 27.6 & 2.3 & 0.82 & $79.8 \rightarrow 77 \cdot 4$ & $11.7 \rightarrow 7.6$ \\
\hline Case-6: $79 \mathrm{M}$ & 29.8 & 2.9 & 1.9 & $81.0 \rightarrow 80.7$ & $7 \cdot 7 \rightarrow 6.9$ \\
\hline Case-7: $83 \mathrm{M}$ & 26.4 & 1.7 & 0.7 & $65.8 \rightarrow 62.0$ & $9.0 \rightarrow 7.8$ \\
\hline \multicolumn{6}{|c|}{ BMI: Body Mass Index, CPR: C-peptide Radioactivity } \\
\hline \multicolumn{6}{|c|}{ CPI $(\mathrm{C}$-peptide index $)=\mathrm{CPR} \times 100 /$ FBG (fasting blood glucose $)$} \\
\hline
\end{tabular}

weight loss in case-1, suggesting clinically significant usefulness $[25,26]$.

Another notable effect would be the effectiveness for mental diseases associated with obesity. Conventionally, administration reports for dementia have been found occasionally, but single-agent administration is rare like case-6 [27]. Furthermore, there are limited cases of continuing at home in schizophrenia such as case-2. In these cases, treatment on GLP-1 RA was successful once a week [38]. In fact, however, various supports from family care and home-visit nursing seem to be essential.

On the other hand, case- 4 showed weight gain with inadequate control even after using dulaglutide. It is necessary to review lifestyle guidance and to consider additional administration of anti-diabetic agents as future issues. In particular, authors would recommend rehabilitation for pain relief, contracture prevention, promote exercise habits, and improve the future care environment.

As mentioned above, dulaglutide was administered to diabetes, and medical and academic discussion was described in this report. To summarize the important points,

I. Dulaglutide was given to super-elderly patients with T2DM on home care, leading to weight reduction and better glycemic control.

II. From the successful result of dulaglutide therapy, we developed GLP-1 RA treatment to other 
Citation: Shirakawa M, Kanamoto Y, Nagaoka H, et al., "Diabetic cases controlled with low carbohydrate diet (LCD) and GLP-1 receptor agonist (GLP-1 RA)”, Asp Biomed Clin Case Rep, vol.2, no.s1: 38-46, 2019.

outpatients in order to improve the quality of diabetic care in remote areas.

III. Depending on the cases, various supports would be essential such as family care and visiting nursing.

\section{References}

[1] Ogurtsova K, da Rocha Fernandes JD, Huang Y, et al., "IDF Diabetes Atlas: global estimates for the prevalence of diabetes for 2015 and 2040". Diabetes Res Clin Pract, vol.128: 40-50, 2017.

[2] Davies MJ, D'Alessio DA, Fradkin J, et al., "Management of Hyperglycemia in Type 2 Diabetes, 2018. A Consensus Report by the American Diabetes Association (ADA) and the European Association for the Study of Diabetes (EASD)". Diabetes Care, vol.41, no.12: 2669-2701, 2018.

[3] Kamishima K, Ogawa H, Jujo K, et al., "Relationships between blood pressure lowering therapy and cardiovascular events in hypertensive patients with coronary artery disease and type 2 diabetes mellitus: The HIJ-CREATE sub-study". Diabetes Res Clin Pract, vol.149: 69-77, 2019.

[4] Gardner CD, Trepanowski JF, Del Gobbo LC, et al., "Effect of Low-Fat vs Low-Carbohydrate Diet on 12Month Weight Loss in Overweight Adults and the Association With Genotype Pattern or Insulin Secretion: The DIETFITS Randomized Clinical Trial”. JAMA, vol.319, no.7: 667-79, 2018.

[5] Ebbeling CB, Feldman HA, Klein GL, et al., "Effects of a low carbohydrate diet on energy expenditure during weight loss maintenance: randomized trial”. BMJ, vol.363: k4583, 2018.

[6] Atkins MD, Robert C, "Dr. Atkins' New Carbohydrate Gram Counter”. M. Evans and Company: 1996.

[7] Shai I, Schwarzfuchs D, Henkin Y, et al., "Dietary Intervention Randomized Controlled Trial (DIRECT) Group. Weight Loss with a Low-Carbohydrate, Mediterranean, or Low-Fat Diet”. $N$ Engl J Med, vol.359, no.3: 229-41, 2008.

[8] Ebe K, Ebe Y, Yokota S, et al., "Low Carbohydrate diet (LCD) treated for three cases as diabetic diet therapy”. Kyoto Medical Association Journal, vol.51: 125-29, 2004.

[9] Bando H, Ebe K, Muneta T, et al., "Clinical Effect of Low Carbohydrate Diet (LCD): Case Report". Diabetes Case Rep, vol.2: 124, 2017.

[10] Muneta T, Kawaguchi E, Nagai Y, et al., "Ketone body elevation in placenta, umbilical cord, newborn and mother in normal delivery”. Glycative Stress Research, vol.3, no.3: 133-40, 2016.

[11] Kreymann B, Williams G, Ghatei MA, et al., "Glucagon-like peptide-1 7-36: a physiological incretin in man”. Lancet, vol.2, no.8571: 1300-04, 1987.

[12] Smith EP, An Z, Wagner C, et al., "The role of $\beta$ cell glucagon-like peptide-1 signaling in glucose regulation and response to diabetes drugs". Cell Metab, vol.19, no.6: 1050-07 doi: , 2014.

[13] Gurung T, Shyangdan DS, O'Hare JP, et al., "A novel, long-acting glucagon-like peptide receptoragonist: dulaglutide”. Diabetes Metab Syndr Obes, vol.8: 363-86, 2015.

[14] Hedrington MS, Davis SN, "Oral semaglutide for the treatment of type 2 diabetes”. Expert Opinion on Pharmacotherapy, vol.20, no.2: 133-41, 2019.

[15] Thompson AM, Trujillo JM, "Dulaglutide: The Newest GLP-1 Receptor Agonist for the Management of Type 2 Diabetes". Ann Pharmacother, vol.49, no.3: 351-59, 2015.

[16] Yabe D, Seino Y, "Defining the role of GLP-1 receptor agonists for individualized treatment of type 2 diabetes”. Expet Rev Endocrinol Metabol, vol.9, no.6: 659-70, 2014.

[17] Usui R, Yabe D, Seino Y, “Twincretin as a potential therapeutic for the management of type 2 diabetes with obesity”. J Diabetes Invest: 2019.

[18] Seino Y, Yabe D, "Glucose-dependent insulinotropic polypeptide and glucagon-like peptide1: Incretin actions beyond the pancreas". J Diabetes Investig, vol.4, no.2: 108-30, 2013.

[19] Terauchi Y, Satoi Y, Takeuchi M, et al., "Monotherapy with the once weekly GLP-1 receptor agonist dulaglutide for 12 weeks in Japanese patients with type 2 diabetes: dose-dependent effects on glycaemic control in a randomised, double-blind, placebo-controlled study”. Endocr J vol.61, no.10: 94959, 2014.

[20] Odawara M, Miyagawa J, Iwamoto N, et al., "Once-weekly glucagon-like peptide-1 receptor agonist 
dulaglutide significantly decreases glycated haemoglobin compared with once-daily liraglutide in Japanese patients with type 2 diabetes: 52 weeks of treatment in a randomized phase III study". Diabetes Obes Metab, vol.18, no.3: 249-57, 2016.

[21] Dungan KM, Povedano ST, Forst T, et al., "Onceweekly dulaglutide versus once-daily liraglutide in metformin-treated patients with type 2 diabetes (AWARD-6): a randomised, open-label, phase 3, noninferiority trial". Lancet, vol.84: 1349-57, 2014.

[22] Hamano K, Nishiyama $H$, Matsui A, et al., "Efficacy and safety analyses across 4 subgroups combining low and high age and body mass index groups in Japanese phase 3 studies of dulaglutide 0.75 $\mathrm{mg}$ after 26 weeks of treatment”. Endocrine Journal, vol.64, no.4: 449-56, 2017.

[23] Bouchonville MF, Hager BW, Kirk JB, et al., "Endo ECHO improves primary care provider and community health worker self-efficacy in complex diabetes management in medically underserved communities". Endocr Pract, vol.24, no.1: 40-46, 2018.
[24] Tsuchie H, Miyakoshi N, Iba K, Kasukawa Y, et al., "The effects of teriparatide on acceleration of bone healing following atypical femoral fracture: comparison between daily and weekly administration”. Osteoporos Int, vol.29, no.12: 265965, 2018.

[25] Marso SP, Daniels GH, Brown-Frandsen K, et al., "Liraglutide and cardiovascular outcomes in type 2 diabetes". N Engl J Med, vol.375:311-22, 2016.

[26] Ferdinand KC, Botros FT, Atisso CM et al., "Cardiovascular safety for once-weekly dulaglutide in type 2 diabetes: a pre-specificate meta-analysis of prospectively adjudicated cardiovascular event”. Cardiovasc Diabetol, vol.15:1-12, 2016.

[27] Dumbrill JL, Moulton CD, "Effects of incretinbased therapies on neurocognitive function in humans: A systematic review of the literature". Prim Care Diabetes, vol.12, no.1: 51-58, 2018.

[28] Lally J, O'Loughlin A, Stubbs B, et al., "Pharmacological management of diabetes in severe mental illness: a comprehensive clinical review of efficacy, safety and tolerability". Expert Rev Clin Pharmacol, vol.11, no.4: 411-24, 2018.

Keywords: Low Carbohydrate Diet (LCD); GLP-1 Receptor Agonist (GLP-1 RA); Dulaglutide; Type 2 Diabetes Mellitus (T2DM); Dipeptidyl Peptidase-4 (DPP-4) Inhibitor; Intestine Secretion Insulin (INCRETIN) 